Progressive Physics Journal
Volume 2, Nomor 1, Juni 2021
ISSN 2722-7707 (online)
http://jurnal.fmipa.unmul.ac.id/index.php/ppj/index

\title{
RANCANG BANGUN SISTEM MONITORING SUHU DAN KELEMBABAN TANAH PADA MEDIA TANAM BERBASIS MIKROKONTROLER ATMEGA328P
}

\author{
Putri Islam Nur Hikmah ${ }^{1,}{ }^{*}$, Mislan $^{1}$, Rahmiati $^{2}$ \\ ${ }^{1}$ Program Studi Fisika, Fakultas MIPA, Universitas Mulawarman \\ ${ }^{2}$ Program Studi Geofisika, Fakultas MIPA, Universitas Mulawarman
}

*E-mail : putriislamnur28@gmail.com

\begin{abstract}
Information of temperature and humidity in planting medium is very important for cultivation activities and the process of plant growth, where the real time process is very useful to determine the watering process on planting medium. The purpose of this research was to design a monitoring system for soil temperature and humidity on the planting medium and to make an automatic plant watering sprinkler by detecting soil moisture. A design for monitoring soil temperature and humidity on planting medium has been made with a microcontroller. This sampling process was done by placing a sensor of temperature and soil moisture on planting medium to get the value of soil temperature and soil moisture. To found out that plant sprinkler instrument has worked by spirt water, when the soil has dry. From this research, the designed instrument worked to monitor soil temperature and humidity on the planting medium by providing information to the user for dry, wet and moist soil. This instrument has worked when the pump detects soil with a range from $0-3 \mathrm{~cm} / \mathrm{Hg}$ for dry, 3.1-6 cm/ $\mathrm{Hg}$ for moist and 6-7.9 $\mathrm{cm} / \mathrm{Hg}$ for wet. When the soil is dry, the pump will work by removing water and stop when the soil is damp or wet. This water sprinkel only worked to detect dry soil conditon.
\end{abstract}

Kata Kunci: Microcontroller, Monitoring, Planting Medium, Soil Moisture, Temperature

\section{PENDAHULUAN}

Perkembangan ilmu pengetahuan dan teknologi (IPTEK) telah memberikan dampak dalam semua bidang kehidupan manusia, tidak terkecuali pada bidang pertanian. Zaman sekarang sudah banyak teknologi canggih yang diciptakan salah satunya teknologi dalam bidang pertanian yang dapat membantu meringankan pekerjaan petani. Inovasi teknologi infromasi dalambidang pertanian adalah penggunaan sensor dan mikrokontroler. Indonesia yang memiliki dua musim dan sebagian besar masyarkat sebagai petani sangat mendukung pengembangan teknologi di bidang pertanian [1].

Kelembaban dan suhu merupakan faktor alam yang sangat berpengaruh dalam bidang pertanian. Semakin lembab tanah, maka tanaman akan mengalami kerusakan atau pembusukan dan sebaliknya bila tanaman memiliki kelembaban yang sesuai, maka tanaman akan tumbuh subur. Suhu tanah berpengaruh terhadap penyerapan air. Semakin rendah suhu, maka sedikit air yang diserap oleh akar. Oleh karena itu, penurunan suhu tanah mendadak dapat menyebabkan kelayuan tanaman [2]. 
Beberapa penelitian tentang rancang bangun suhu dan kelembaban tanah telah dilakukan oleh Sintia [1] dan Lutfiyana [3]. Pada penelitian-penelitian sebelumnya hanya membahas tentang suhu tanah dan kelembaban tanah serta mengukur suhu udara pada tanaman. Pada penelitian sebelumnya juga suhu diukur dengan menggunakan alat DHT11 dan DS118B20. Pada penelitian Husdi [4], penelitian hanya menggunakan sensor kelembaban tanah untuk memonitoring keadaan tanah saja yang dapat di monitor secara online. Namun, penelitian rancang bangun tentang suhu dan kelembaban tanah untuk sistem monitoring serta alat otomatis penyiram tanaman dengan mendeteksi kondisi kelembaban yang terdapat didalam tanah belum banyak dilakukan.

Rancang bangun sistem monitoring pada tanaman agar suhu tanah dan kelembaban tanahnya tetap terjaga, serta dapat mengahasilkan tanaman yang subur. Rancang bangun ini dapat menyiram tanaman secara otomatis dengan mendeteksi kelembaban tanah yang terdeteksi oleh sensor kelembaban tanah (YL-69). Pada penelitian ini kita dapat memanfaatkan teknologi yang ada dan memanfaatkannya pada bidang pertanian. Penelitian ini juga diharapkan dapat memberikan informasi mengenai suhu dan kelembaban tanah pada media tanam serta dapat mempermudah pekerjaan manusia dalam segi tenaga dan efisien waktu dalam proses penyiraman.

\section{TINJAUAN PUSTAKA}

\section{Suhu}

Menurut Djumali dan Mulyaningsih [5] secara umum, suhu dan kelembaban tanah merupakan unsur yang berpengaruh terhadap pertumbuhan tanaman. Suhu tanah akan dipengaruhi oleh jumlah serapan radiasi matahari oleh permukaan tanah. Suhu tanah pada saat siang dan malam berbeda, pada siang hari ketika permukaan tanah dipanasi matahari, udara yang dekat dengan permukaan tanah memperoleh suhu yang tinggi, sedangkan pada malam hari suhu tanah semakin menur un. Suhu tanah berpengaruh terhadap penyerapan air. Semakin rendah suhu, maka sedikit air yang diserap oleh akar. Oleh karena itulah, penurunan suhu tanah mendadak dapat menyebabkan kelayuan tanaman [2].

\section{Kelembaban Tanah}

Kelembaban tanah adalah jumlah air yang tersimpan di antara pori-pori tanah. Kelembaban tanah sangat dinamis disebabkan oleh penguapan melalui permukaan tanah, transpirasi, dan perkolasi. Kelembaban tanah memiliki peranan yang penting bagi pemerintah untuk mengetahui informasi seperti potensi aliran permukaan dan pengendali banjir, keggalan erosi tanah dan kemiringan lereng, manajemen sumber daya air, geoteknik, dan kualitas air. Faktor-faktor yang menentukan kelembaban tanah adalah curah hujan, jenis tanah, dan laju evapotranspirasi, dimana kelembaban tanah akan menentukan ketersediaan air dalam tanah bagi pertumbuhan tanaman [2].

Ukuran kelembaban/lengas tanah adalah $\mathrm{cm} \mathrm{Hg}$, bar dan $\mathrm{pF}$ dimana satuan $\mathrm{cm}$ air dibagi 1000 menjadi satuan bar.

$$
1 \text { bar }=0,9869 \mathrm{~atm}=10^{5} \mathrm{Pascal}=75,007 \mathrm{~cm} \mathrm{Hg}
$$

Kelembaban tanah adalah banyaknya air yang terkandung pada tanah yang umumnya didefinisikan sebagai bandingan massa air terhadap massa tanah kering $[6]$.

\section{ATMEGA328P}

Arduino Uno merupakan versi terbaru dari keluarga Arduino, berbasis mikrokontroler ATMEGA328P, menyempurnakan tipe sebelumnya, Duemilanove. Perbedaan Arduino tersebut 
adalah tidak menggunakan IC FTDI (Future Technology Devices International) USB to Serial sebagai driver komunikasi USB-nya, tetapi menggunakan mikrokontroler ATMEGA8U2 yang di program sebagai konverter USB ke serial. Uno sendiri diambil dari bahasa Italia yang artinya 1 (satu). Gambar 1 adalah board Arduino Uno dengan spesifikasi hardware:

- Mikrokontroler: ATMEGA328

- Tegangan Operasi : 5V

- Tegangan Input : 7 - 12V

- Digital I/O : 14 pin

- PWM : 6 channel

- Analog Input : 6 channel

- Memory : 32KB Flash PEROM (0,5 KB digunakan oleh bootloader), 2KB SRAM dan 1KB EEPROM

- Frekuensi Clock : $16 \mathrm{MH}$

[7].

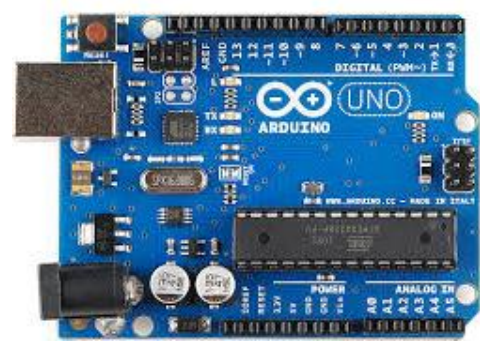

Gambar 1. Papan Arduino

\section{Liquid Crystal Display}

Liquid crystal display (LCD) adalah komponen yang dapat menampilkan tulisan. Salah satu jenisnya memiliki dua baris dengan setiap baris terdiri atas enam belas karakter. LCD seperti itu biasa disebut LCD 16×2 [8]. Dipasaran tampilan LCD sudah tersedia dalambentuk modul yaitu tampilan LCD beserta rangkaian pendukungnya termauk ROM dan sebagainya. LCD mempunyai pin data, kontrol catu daya dan pengatur kontras tampilan [9].

\section{Pompa Air}

Pompa adalah mesin atau peralatan mekanis yang digunakan untuk menaikan cairan dari dataran rendah ke dataran tinggi atau untuk mengalirkan cairan dari daerah bertekanan rendah ke daerah yang bertekanan tinggi dan juga sebagai penguat laju aliran pada suatu sistem jaringan perpipaan. Prinsip kerja pompa adalah dengan melakukan penekanan dan penghisapan terhadap fluida. Pada sisi hisap pompa (suction), elemen pompa akan menurunkan tekanan dalam ruang pompa sehingga akan terjadi perbedaan tekanan antara permukaan fluida yang dihisap dengan ruang pompa [10].

\section{LM 35}

Dalam mengukur perubahan suhu yang terjadi digunakan sensor suhu LM 35 dan termometer sebagai pebanding suhu keluaran LM 35. LM 35 merupakan sensor dalam bentuk IC yang memiliki kecermatan tinggi. IC berfungsi untuk mengubah suhu lingkungan menjadi sinyal listrik dimana tegangan keluarannya proporsional terhadap derajat Celcius $\left({ }^{\circ} \mathrm{C}\right)$ dengan koefisien sebesar $10 \mathrm{mV} /{ }^{\circ} \mathrm{C}$ untuk setiap kenaikan suhu $1{ }^{\circ} \mathrm{C}$. Sensor LM 35 akan memiliki nilai tahanan yang berbanding terbalik dengan perubahan suhu lingkungan, yaitu nilai tahanan akan meningkat jika temperatur rendah dan sebaliknya. Keuntungan lain dari sensor LM 35 adalah memberikan akurasi sebesar $\pm 1 / 4{ }^{\circ} \mathrm{C}$ pada suhu ruangan dan $\pm 3 / 4{ }^{\circ} \mathrm{C}$ terhadap suatu rentang suhu 
$-55{ }^{\circ} \mathrm{C}$ hingga $+150{ }^{\circ} \mathrm{C}$ tanpa keluaran LM 35 yang rendah, keluaran linier, dan proses kalibrasi yang mudah dan tepat sehingga dapat dibaca dan diatur sirkulasinya serta dapat menggunakan catu daya tunggal atau dengan catu daya plus (+) dan minus (-) [11].

\section{Relay}

Relay adalah saklar (switch) yang dioperasikan secara listrik dan merupakan komponen elektromechanical (elektromekanikal) yang terdiri dari dari 2 bagian utama, yakni elektromagnet (coil) dan mekanikal (seperangkat kontak saklar/switch). Relay menggunakan prinsip elektromagnetik untuk menggerakkan kontak saklar sehingga dengan arus listrik yang kecil (low power) dapat menghantarkan listrik yang bertegangan lebih tinggi [12]. Cara kerja komponen ini dimulai pada saat mengalirnya arus listrik melalui coil, lalu membuat medan magnet sekitarnya sehingga dapat merubah saklar yang ada di dalam relay tersebut. Pemakaian relay dalam perangkat-perangkat elektronika mempunyai keuntungan, yaitu dapat mengontrol sendiri arus serta tegangan listrik yang diinginkan, dapat memaksimalkan besarnya tegangan listrik hingga mencapai batas maksimalnya, dan dapat menggunakan baik saklar maupun coil lebih dari satu, di sesuaikan dengan kebutuhan [9].

\section{Sensor Kelembaban Tanah}

Sensor kelembaban tanah jenis YL-69 merupakan sensor kelembaban yang mendeteksi kelembaban tanah. Satu set sensor kelenbaban tipe YL-69 terdiri dari YL-69 sebagai probe sensor dan YL-39 sebagai modul pengkondisian sinyal. Sensor kelembaban tipe YL-69 terdapat sebuah modul yang didalamnya terdapat IC LM393 yang berfungsi untuk proses pembanding offset rendah yang lebih rendah dari $5 \mathrm{mV}$ yang stabil dan presisi [3].

Sensor kelembaban YL-69 dapat membaca kadar air yang memiliki 3 kondisi yaitu:

- $0-300$ : tanah kering atau udara bebas

- $300-700$ : tanah lembab

[3].

- $700-950$ : tanah basah (di dalam air)

\section{METODE PENELITIAN}

\section{Waktu dan Tempat Penelitian}

Penelitian ini dilaksanakan pada bulan Februari 2020 sampai dengan bulan Februari 2021 bertempat di Laboratorium Elektronika dan Instrumentasi, Fakultas Matematika dan IImu Pengetahuan Alam, Kampus Gunung Kelua, Universitas Mulawarman, Kota Samarinda, Provinsi Kalimantan Timur.

\section{Alat dan Bahan Penelitian}

Alat yang digunakan dalam penelitian ini adalah mikrokontroler ATMEGA328P sebagai pengendali, LCD sebagai pembaca keterangan, sensor LM35 sebagai sensor suhu, sensor YL-69 sebagai sensor kelembaban tanah, relay sebagai pengatur otomatis pompa, pompa air sebagai alat yang mengeluarkan air.

Bahan yang digunakan dalam penelitian ini adalah media tanam bayam sebagai objek yang diukur untuk menggunakan alat yang dibuat. Gambar 2 menampilkan design rangkaian elektronik yang digunakan pada penelitian ini. Adapun masing-masing bagian pada Gambar 2 yakni sebagai berikut; (1)Sensor kelembaban, (2)Sensor Suhu, (3)LCD, (4)Arduino, (5)Relay, (6)Pompa, (7)Potensiometer, (8)Kabel Penghubung. 


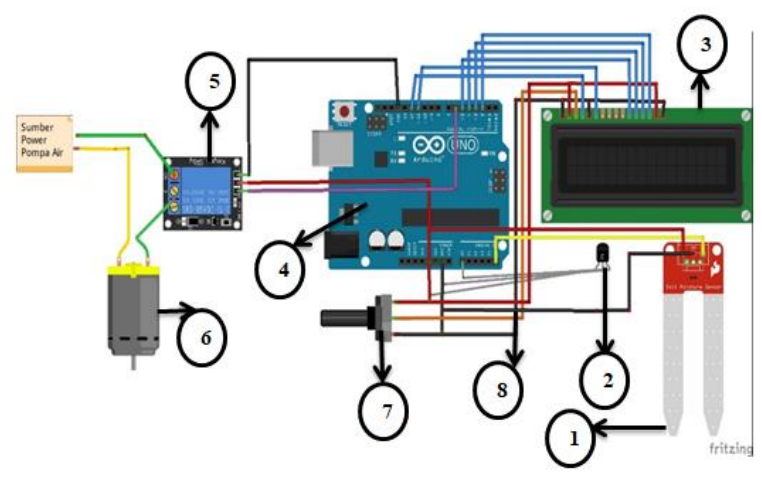

Gambar 2. Design Rangkaian Elektronik.

\section{Prosedur Penelitian}

Hal pertama yang dilakukan adalah melakukan perencanaan alat dan pembuatan alat. Setelah alat dibuat, maka alat diujikan pada media tanam tanaman. Alat ini bekerja dengan membaca kondisi tanah (kelembaban tanah) saat sensor di letakan di tanah (media tanam). Pada saat tanah dalam kondisi kering, maka alat akan mengeluarkan air dan pada kondisi basah/lembab alat hanya membaca nilai kondisi tanah. Terbacanya suhu dan kelembaban tanah pada alat yang dibuat dan terjadi proses penyiraman pada media tanam.

\section{Tahap Pengambilan Data}

Pengambilan data monitoring suhu dan kelembaban sekaligus pengujian alat ini dilakukan di kediaman peneliti dengan selang waktu pengamatan \pm per 3 menit atau lebih sekaligus menguji alat apa dapat bekerja dengan mengeluarkan air dalam kondisi tanah kering.

Tabel 1. Hasil Monitoring

\begin{tabular}{cccccc}
\hline No Waktu & $\begin{array}{c}\text { Suhu } \\
{ }^{\circ} \mathrm{C}\end{array}$ & \multicolumn{2}{c}{ Kelembaban } & \multicolumn{2}{c}{ Pompa } \\
& & Nilai & Kondisi & On & Off \\
\hline
\end{tabular}

\section{HASIL DAN PEMBAHASAN}

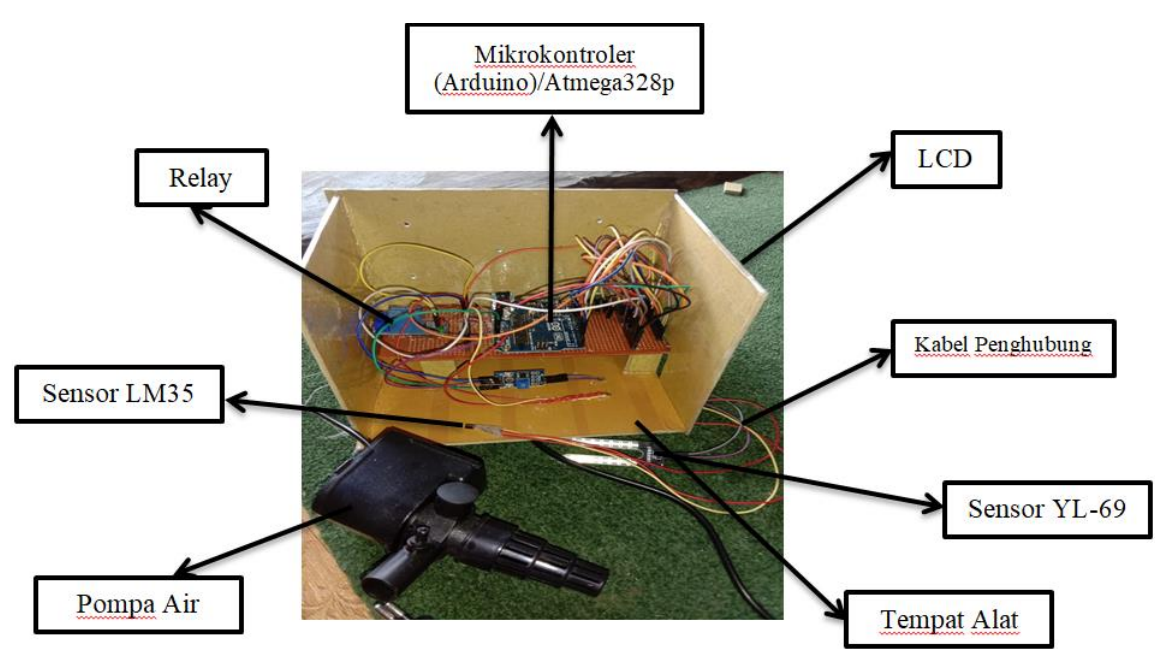

Gambar 3. Rancangan Sensor Suhu dan Kelembaban Tanah Menggunakan LM35 dan YL-69 untuk Sistem Monitoring serta Penyiraman Tanaman Otomatis Berbasis

Mikrokontroler 
Alat monitoring suhu dan kelembaban tanah ini terdiri dari dua buah sensor, yakni sensor LM35 sebagai sensor suhu dan sensor YL-69 sebagai sensor kelembaban tanah. Pada komponen ATMEGA328P (Arduino) sebagai pengendali untuk kedua sensor tersebut. Relay yang berfungsi sebagai saklar otomatis untuk pompa airnya agar dapat dihubungkan dengan Arduino. Serta LCD berfungsi untuk memberikan keterangan yang dikeluarkan atau dihasilkan oleh kedua sensor tersebut.

Adapun hasil monitoring dari rancang bangun yang dibuat dari penelitian ini, yakni sebagai berikut:

Tabel 2. Data Monitoring Suhu dan Kelembaban

\begin{tabular}{|c|c|c|c|c|c|c|}
\hline \multirow[t]{2}{*}{ No } & \multirow[t]{2}{*}{ Waktu } & \multirow{2}{*}{$\begin{array}{c}\text { Suhu Tanah } \\
{ }^{\circ} \mathrm{C}\end{array}$} & \multicolumn{2}{|c|}{$\begin{array}{c}\text { Kelembaban } \\
\text { Tanah }\end{array}$} & \multicolumn{2}{|c|}{ Pompa } \\
\hline & & & Nilai & Kondisi & On & Off \\
\hline 1 & 09:30 & 29.99 & 1.23 & Kering & $\mathrm{V}$ & \\
\hline 2 & 09:33 & 28.44 & 6.26 & Basah & & V \\
\hline 3 & 09:36 & 28.53 & 6.14 & Basah & & V \\
\hline 4 & 09:39 & 28.84 & 6.07 & Basah & & V \\
\hline 5 & 09:42 & 29.53 & 5.99 & Lembab & & V \\
\hline 6 & 09:45 & 29.29 & 5.96 & Lembab & & V \\
\hline 7 & 09:48 & 29.29 & 5.83 & Lembab & & V \\
\hline 8 & 09:51 & 29.29 & 5.83 & Lembab & & V \\
\hline 9 & 09:54 & 29.29 & 5.78 & Lembab & & V \\
\hline 10 & 09:57 & 29.16 & 4.52 & Lembab & & V \\
\hline 11 & 10:00 & 29.16 & 4.49 & Lembab & & $v$ \\
\hline 12 & 10:03 & 29.06 & 4.44 & Lembab & & V \\
\hline 13 & 10:06 & 29.06 & 4.42 & Lembab & & V \\
\hline 14 & 10:09 & 29.06 & 4.43 & Lembab & & V \\
\hline 15 & 10:12 & 28.82 & 4.32 & Lembab & & V \\
\hline 16 & 10:15 & 28.82 & 4.32 & Lembab & & $v$ \\
\hline 17 & $10: 18$ & 28.59 & 3.55 & Lembab & & V \\
\hline 18 & $10: 21$ & 28.35 & 3.54 & Lembab & & $v$ \\
\hline 19 & $10: 24$ & 29.76 & 2.66 & Kering & $v$ & \\
\hline 20 & $10: 27$ & 28.35 & 6.40 & Basah & & $v$ \\
\hline 21 & 10:30 & 28.59 & 6.26 & Basah & & $v$ \\
\hline 22 & 10:33 & 28.59 & 6.16 & Basah & & $v$ \\
\hline 23 & 10:36 & 29.06 & 6.07 & Basah & & $v$ \\
\hline 24 & 10:39 & 29.16 & 5.53 & Lembab & & $v$ \\
\hline 25 & 10:42 & 29.29 & 5.36 & Lembab & & $v$ \\
\hline 26 & $10: 45$ & 29.29 & 5.31 & Lembab & & V \\
\hline
\end{tabular}

Dari data monitoring di atas saat pertama kali didapatkan tanah dalam kondisi kering karena saat melakukan monitoring dan pengujian alat pertama kali tanah dalam kondisi kering. Alat ini bekerja dengan mendeteksi tanah dalam kondisi kering sehingga alat dapat mengeluarkan air pada tanaman secara otomatis. Selanjutnya, monitoring akan tetap berjalan dengan memberi informasi saat tanah dalam kondisi lembab atau basah pada media tanam tersebut.

Pengujian untuk penggunaan alat dilakukan beberapa kali agar dapat mencapai nilai yang sesuai atau mendekati. Tanah kering memiliki nilai yang rendah sedangkan untuk tanah basah 
memiliki nilai yang tinggi. Ini dikarenakan alat mengikuti nilai dari alat yang asli, yakni alat pengukur kelembaban tanah. Dalam mendapatkan hasil nilai kelembaban di atas, maka dilakukan kalibrasi dengan menggunakan alat asli dan sensor YL-69 hingga diperoleh nilai yang mendekati nilai asli dari alat yang ada.

Berdasarkan penelitian ini, telah dirancang sistem monitoring dan penyiraman tanaman otomatis dengan menggunakan sensor LM35 dan YL-69. Penyiraman tanaman dibuat dengan mendeteksi kelembaban tanah (kering dan basah) oleh sensor YL-69. Saat tanah dalam keadaan kering, maka sensor akan memonitoring keadaan tanah dan pompa air yang dihubungkan ke relay akan bekerja sesuai kondisi tanah. Saat tanah dalam keadaan basah, maka pompa air tidak akan mengeluarkan air. Nilai yang dikeluarkan oleh sensor suhu dan kelembaban akan ditampilkan di LCD.

Pada saat pembuatan alat terjadi beberapa masalah, yakni suhu yang digabungkan dengan sensor kelembaban tidak stabil. Hal ini terjadi karena mikrokontroler membagi tegangan dengan beberapa komponen lainnya. Sensor yang memiliki nilai yang sangat sensitif terhadap lingkungan.

\section{KESIMPULAN}

Berdasarkan penelitian ini, alat yang dirancang dapat bekerja untuk memonitoring suhu dan kelembaban tanah pada media tanam dengan memberikan keterangan pada pengguna untuk tanah kering, basah dan lembab. Alat yang dirancang akan bekerja dengan mengeluarkan air apabila kondisi tanah dalam keadaan kering dan apabila tanah dalam keadaan basah alat tidak akan mengeluarkan air. Alat penyiram tanaman ini hanya bekerja dengan mendeteksi kondisi tanah dalam keadaan kering.

\section{UCAPAN TERIMA KASIH}

Ucapan terima kasih penulis ucapkan kepada Bapak Dr. Mislan M.Si., ibu Rahmiati M.Sc ., Dr. Syahrir, M.Si dan Ibu Devina Rayzy Perwitasari Sutaji Putri, S.Si., M.Sc. yang telah mendukung sehingga penelitian ini dapat diselesaikan. Kepada semua pihak-pihak yang telah membantu yang tidak dapa disebutkan semuanya. Terima kasih.

\section{DAFTAR PUSTAKA}

[1] Sintia, Wulantika dkk. 2018. Rancang Bangun Sistem Monitoring Kelembaban Tanah dan Suhu Udara Berbasis GSM SIM900A DAN ARRDUINO UNO. Universitas Bengkulu. Bengkulu.

[2] Karyati, dkk. 2018. Suhu Dan Kelembaban Tanah Pada Lahan Revegetasi Pasca Tambang Di PT Adimitra Baratama Nusantara, Provinsi Kalimantan Timur. Universitas Mulawarman. Samarinda.

[3] Lutfiyana, dkk. 2017. Rancang Bangun Alat Ukur Suhu Tanah, Kelembaban Tanah, dan Resistansi. Universitas Negeri Semarang. Semarang.

[4] Husdi. 2018. Monitoring Kelembaban Tanah Pertanian Menggunakan Soil Moisture Sensor FC-28 dan Arduino Uno. Universitas Ichsan Gorontalo. Gorontalo. Vol.10, No.2 Agustus 2018.

[5] Djumali dan Mulyaningsih, S. 2014. Pengaruh Kelembaban Tanah Terhadap Karakter Argronomi, Hasil Rajangan Kering Dan Kadar Nikotin Tembakau (Nicotiana Tabacum L; Solonaceae) Temanggung Pada Tiga Jenis Tanah. Balai Penelitian Tanaman Pemanis Dan Serat. Berita Biologi. Malang. 
[6] Amaru, Kharistya. 2014. Hubungan Air, Tanah dan Tanaman. Universitas Padjadjaran. Jawa Barat.

[7] Rinaldi, Aditya. 2018. Modul Teori dan Praktikum Mikrokontroler Platform Arduino. Universitas Mulawarman. Samarinda.

[8] Kadir, Abdul. 2017. Pemograman Arduino dan Processing. PT Elex Media Komputindo. Jakarta.

[9] Sinaulan M., Olivia, dkk. 2015. Perancangan Alat Ukur Kecepatan Kendaraan Menggunakan ATmega 16. UNSRAT. Manado.

[10] Iqtimal, Zian dkk. 2018. Aplikasi Sistem Tenaga Surya Sebagai Sumber Tenaga Listrik Pompa Air. Universitas Siah Kuala. Banda Aceh.

[11]Indriani, Anizar dkk. 2014. Pemanfaatan Sensor Suhu LM 35 Berbasis Microcontroller ATmega 8535 pada Sistem Pengontrolan Temperatur Air Laut Skala Kecil. Universitas Bengkulu. Bengkulu. Vol.5, No.2 Tahun 2014: 183-192.

[12] Saleh, Muhamad dan Munnik Haryanti. 2017. Rancang Bangun Sistem Keamanan Rumah Menggunakan Relay. Universitas Suryadarma. Jakarta. Vol. 8 No. 3 September 2017. 